\title{
Efficacy of alfacalcidol and alendronate on lumbar bone mineral density in osteoporotic patients using proton pump inhibitors
}

\author{
DAISUKE ASAOKA ${ }^{1}$, AKIHITO NAGAHARA ${ }^{2}$, MARIKO HOJO ${ }^{1}$, \\ KENSHI MATSUMOTO ${ }^{1}$, HIROYA UEYAMA ${ }^{1}$, KOHEI MATSUMOTO ${ }^{1}$, \\ KENTARO IZUMI $^{1}$, TSUTOMU TAKEDA ${ }^{1}$, HIROYUKI KOMORI ${ }^{1}$, \\ YOICHI AKAZAWA ${ }^{1}$, YUJI SHIMADA ${ }^{2}$, TARO OSADA ${ }^{1}$ and SUMIO WATANABE ${ }^{1}$ \\ ${ }^{1}$ Department of Gastroenterology, School of Medicine, University of Juntendo, Tokyo 113-8421; \\ ${ }^{2}$ Department of Gastroenterology, Juntendo University Shizuoka Hospital, Shizuoka 410-2295, Japan
}

Received April 14, 2016; Accepted June 24, 2016

DOI: 10.3892/br.2016.710

\begin{abstract}
It has been indicated that proton pump inhibitor (PPI) use is associated with a loss of the anti-fracture efficacy of alendronate $(\mathrm{AD})$. However, there are few prospective studies that have investigated the efficacy of AD on lumbar bone mineral density (BMD) in osteoporotic patients who are using PPIs. Thus, the aim of the present study was to investigate the efficacy of alfacalcidol (AC) and AD on lumbar BMD in osteoporotic patients using PPIs. A prospective, randomized, active control study enrolled such osteoporotic patients (age, $\geq 50$ years). The patients were randomly assigned to receive $\mathrm{AC}(1 \mu \mathrm{g} /$ day $)$ or $\mathrm{AD}(35 \mathrm{mg} /$ week) and were followed up for one year. Patient profiles were maintained, and lumbar BMD, bone-specific alkaline-phosphatase (BAP) and collagen type-I cross-linked N-telopeptide (NTX), upper gastrointestinal endoscopy results, and the frequency scale for the symptoms of gastroesophageal reflux disease (FSSG) were evaluated. Percentage changes in lumbar BMD, NTX, BAP, and change in FSSG score from baseline to the end of one year of treatment were investigated. Sixteen patients were eligible for analysis (eight assigned to receive AC, eight assigned to receive $\mathrm{AD}$ ). The percentage change in lumbar BMD from baseline to the end of treatment was $-0.4 \pm 4.0 \%$ for the $\mathrm{AC}$ group vs. $6.8 \pm 6.3 \%$ for the $\mathrm{AD}$ group $(\mathrm{P}=0.015)$. No significant percentage change of BAP and NTX between the two groups was observed. Subsequent to one year of treatment, the FSSG score did not change from the baseline values for either study group, and no new bone fractures or esophagitis were observed in either group of patients. The findings demonstrated that in osteoporotic patients using concomitant PPIs, there was a greater increase in lumbar BMD after one year of treatment with AD compared with AC. However, the number of study
\end{abstract}

Correspondence to: Dr Daisuke Asaoka, Department of Gastroenterology, School of Medicine, University of Juntendo, 2-1-1 Hongo, Tokyo 113-8421, Japan

E-mail: daisuke@juntendo.ac.jp

Key words: osteoporosis, alendronate, alfacalcidol, prospective, randomized, proton pump inhibitor subjects was small; thus, further, large prospective studies are required to determine the effect of $\mathrm{AD}$ in osteoporotic patients using concomitant PPIs.

\section{Introduction}

With a rapidly aging population, osteoporosis is a significant concern in Japan. While it is asymptomatic, osteoporosis progresses gradually, leading to hip and lumbar fractures, which may require extended nursing care and threaten life expectancy (1). Therefore, prevention of osteoporosis is important and the efficacy of bisphosphonates in osteoporosis treatment has been supported by previous studies (2). However, side effects of bisphosphonate use are gastrointestinal (GI) disorders $(3,4)$. In the 'super-aging' Japanese society, consumption of non-steroidal anti-inflammatory drugs (NSAIDs) and aspirin increases with the greater incidence of joint, ischemic heart and cerebrovascular diseases, with NSAID-induced GI disorders becoming an increasing concern $(5,6)$. In addition, gastric acid secretion in Japanese patients has gradually increased due to a trend towards Westernized eating habits (7) and a decrease in Helicobacter pylori infections, with the number of gastroesophageal reflux disease (GERD) patients also increasing rapidly (8). Proton pump inhibitors (PPIs) are key first-line therapeutic strategies for the treatment of NSAID-induced ulcers and GERD (9). PPIs are often administered as a long-term treatment, and it is common for PPIs to be used concomitantly with bisphosphonates. A previous study suggested that PPI use was associated with a dose-dependent loss of the anti-fracture efficacy of alendronate (AD) (10). However, there are few prospective studies that investigate the efficacy of $\mathrm{AD}$ on lumbar bone mineral density (BMD) in osteoporotic patients using concomitant PPIs. The aim of the present study was to investigate the efficacy of AD on lumbar BMD in osteoporotic patients using concomitant PPIs, comparing the effects versus alfacalcidol (AC) in a prospective, randomized, open-label, comparative study.

\section{Materials and methods}

Study design. The present study was conducted as a prospective, randomized, open-label, active control, comparative, 
single-center study. From 2009 until 2013 at Juntendo University Hospital (Tokyo, Japan), osteoporotic patients (age, $\geq 50$ years) who were using PPIs were enrolled in the study. After assignment to the $\mathrm{AC}(1 \mu \mathrm{g} /$ day $)$ or $\mathrm{AD}(35 \mathrm{mg} / \mathrm{week})$ groups, the patients were followed up for one year of treatment. The AD group patients took the medication in the early morning (after an overnight fast) with a glass of plain water, and were instructed to remain upright for $\geq 30 \mathrm{~min}$ before consuming the first food of the day. Patients from the two groups were prohibited from taking any other medication affecting bone or calcium metabolism during the treatment period. Patient profiles [age, gender, body mass index (BMI), alcohol consumption, smoking, comorbidities (type 2 diabetes mellitus and hypertension)] and ongoing concomitant medications [calcium channel blockers (CCBs), low-dose aspirin (LDAA), and 3-hydroxy-3-methylglutaryl-coenzyme A (HMG-CoA) reductase inhibitors] were evaluated. BMI was calculated as body weight divided by the square of body height in meters $\left(\mathrm{kg} / \mathrm{m}^{2}\right)$. Patients that had used standard doses of CCBs, LDAA, or HMG-CoA reductase inhibitors for $>6$ months were identified as users of that specific therapy. We defined the cases that used the usual dose of PPIs (10 mg rabeprazole or $20 \mathrm{mg}$ omeprazole or $30 \mathrm{mg}$ lansoprazole) for $>6$ months as users of that specific therapeutic strategy. The study was conducted in accordance with the Declaration of Helsinki. The Juntendo University Ethics Committee approved this study protocol (reference no. 207-028) and patients signed an Ethics Committee-approved informed consent document.

Exclusion criteria. Patients with osteoporosis were selected for the present study, however, certain individuals were excluded according to the following criteria: Patients who were currently or previously being treated with glucocorticoids, hormone replacement therapy, thyroid/parathyroid medication, psychotropic medication, anticonvulsants, selective estrogen receptor modulators or calcium were excluded. Patients with the following conditions were also excluded: Gastrectomy, inflammatory bowel disease, malignant disease (gastric, esophageal, colon, lung, pancreatic, liver, bile duct, gallbladder, breast, uterine, ovarian, prostate, and bladder cancer, malignant lymphoma, leukemia and multiple myeloma), chronic kidney disease, type 1 diabetes mellitus, hypo/hyper-thyroidism, hypo/hyper-parathyroid disorder, rheumatoid arthritis (including other collagen diseases), and those female patients who were premenopausal.

Measurement of lumbar BMD. BMD at lumbar vertebrae 2 through 4 (L2-4) was measured by dual-energy X-ray absorptiometry using a Discovery DXA ${ }^{\circledR}$ system (Hologic; Bedford, MA, USA) and the presence of fragility fractures were investigated in the chest and lumbar spine using lateral vertebral $\mathrm{X}$-rays. The diagnosis of osteoporosis was performed in accordance with the 2000 version of the Japanese Diagnostic Criteria of the Japanese Society for Bone and Mineral Research (11). Degenerative lesions of the vertebrae were ruled out on diagnosing osteoporosis. An osteoporotic patient was defined as one having lumbar BMD values $<70 \%$ of the young adult mean (YAM) in those without any prevalent fragility fracture. Osteoporosis was also defined as the presence of fragility fractures of any bone in a person with a BMD of
$<80 \%$ of the YAM. Percentage change of lumbar BMD was evaluated from baseline to the end of one year of treatment in the $\mathrm{AC}$ and $\mathrm{AD}$ groups.

Measurement of bone turnover markers. Serum bone-specific alkaline-phosphatase (BAP; a biomarker of bone formation) and serum collagen type I cross-linked N-telopeptide (NTX; a biomarker of bone resorption) were examined. Percentage changes of NTX and BAP from baseline to the end of one year of treatment were investigated in the $\mathrm{AC}$ and $\mathrm{AD}$ groups.

Upper GI findings and frequency scale for the symptoms of GERD (FSSG). The prevalence rate of upper GI endoscopy findings were analyzed, including reflux esophagitis (RE), hiatal hernia (HH) and peptic ulcer disease (PUD). RE was defined as grade A, B, C, or D according to the Los Angeles Classification (12), and PUD as a gastric and/or duodenal ulcer or ulcer scar. HH was defined as an apparent separation of the esophagogastric junction and diaphragm impression by $>2 \mathrm{~cm}$ at endoscopy. The FSSG score was established via questionnaire (13). Changes in the FSSG score from the baseline to the end of one year of treatment, and findings of upper GI endoscopy (RE, HH and PUD) at baseline and the end of one year of treatment were evaluated.

Endpoint. In addition, the safety of use of the two therapeutic agents over time was evaluated by assessing the side effects experienced by patients in each group.

Statistical analysis. The baseline characteristics were compared between the AC and AD groups by paired t-test or Fisher's exact test. The percentage change from baseline to the end of one year of treatment for lumbar BMD, NTX, and BAP was investigated by paired $t$-test. The change of FSSG score from baseline to the end of one year of treatment in each group was also investigated by paired t-test and $\mathrm{P}<0.05$ was considered to indicate a statistically significant difference.

\section{Results}

Baseline characteristics. Of the 22 patients enrolled in the present study, six were excluded from evaluation [three patients in the AC group (one was excluded due to medication side effects, one due to other disease, and one dropped out of the study) and three patients in the AD group (one due to medication side effects and two dropped out of the study)].

The baseline characteristics are summarized in Table I. Of the 16 eligible patients, eight received $\mathrm{AC}$ treatment and eight received $\mathrm{AD}$ treatment. In the $\mathrm{AC}$ and $\mathrm{AD}$ groups, respectively, 1 case vs. 3 cases received rabeprazole; 5 cases vs. 1 case received omeprazole; and 2 cases vs. 4 cases received lansoprazole. As shown in Table I, there were no significant differences in baseline characteristics between the two treatment groups. There were no patients with fractures at the beginning of the study.

Lumbar BMD. Baseline values of lumbar BMD were $0.62 \pm 0.14 \mathrm{~g} / \mathrm{cm}^{2}$ for the AC group and $0.70 \pm 010 \mathrm{~g} / \mathrm{cm}^{2}$ for the $\mathrm{AD}$ group $(\mathrm{P}=0.182)$. Following one year of treatment, the lumbar BMD values were $0.61 \pm 0.12 \mathrm{~g} / \mathrm{cm}^{2}$ for the $\mathrm{AC}$ group 
Table I. Patient baseline characteristics .

\begin{tabular}{|c|c|c|c|c|}
\hline Patient profile & Total $(n=16)$ & Alfacalcidol $(\mathrm{n}=8)$ & Alendronate $(\mathrm{n}=8)$ & P-value \\
\hline Age, years & $64.1 \pm 9.0$ & $64.9 \pm 10.1$ & $63.3 \pm 8.4$ & 0.730 \\
\hline Gender, n (\%) & & & & 1.000 \\
\hline Male & $4(25.0)$ & $2(25.0)$ & $2(25.0)$ & \\
\hline Female & $12(75.0)$ & $6(75.0)$ & $6(75.0)$ & \\
\hline Body mass index $\left(\mathrm{kg} / \mathrm{m}^{2}\right)$ & $20.8 \pm 3.8$ & $19.6 \pm 3.0$ & $21.9 \pm 4.3$ & 0.230 \\
\hline Alcohol consumption, n (\%) & & & & 1.000 \\
\hline Non-drinker & $15(93.8)$ & $7(87.5)$ & $8(100.0)$ & \\
\hline Drinker & $1(6.2)$ & $1(12.5)$ & $0(0.0)$ & \\
\hline Smoking, n (\%) & & & & 0.569 \\
\hline Non-smoker & $12(75.0)$ & $7(87.5)$ & $5(62.5)$ & \\
\hline Smoker & $4(25.0)$ & $1(12.5)$ & $3(37.5)$ & \\
\hline \multicolumn{5}{|l|}{ Comorbidities } \\
\hline Diabetes mellitus, n (\%) & & & & 1.000 \\
\hline No & $15(93.8)$ & $7(87.5)$ & $8(100.0)$ & \\
\hline Yes & $1(6.2)$ & $1(12.5)$ & $0(0.0)$ & \\
\hline Hypertension, n (\%) & & & & 0.569 \\
\hline No & $12(75.0)$ & $7(87.5)$ & $5(62.5)$ & \\
\hline Yes & $4(25.0)$ & $1(12.5)$ & $3(37.5)$ & \\
\hline \multicolumn{5}{|l|}{ Concomitant medications } \\
\hline Calcium channel blocker, n (\%) & & & & 1.000 \\
\hline Non-user & $13(81.3)$ & $7(87.5)$ & $6(75.0)$ & \\
\hline User & $3(18.7)$ & $1(12.5)$ & $2(25.0)$ & \\
\hline Low dose aspirin, $\mathrm{n}(\%)$ & & & & 1.000 \\
\hline Non-user & $10(62.3)$ & $5(62.5)$ & $5(62.5)$ & \\
\hline User & $6(37.6)$ & $3(37.5)$ & $3(37.5)$ & \\
\hline $\begin{array}{l}\text { 3-hydroxy-3-methylglutaryl-coenzyme A } \\
\text { reductase inhib-itors, } \mathrm{n}(\%)\end{array}$ & & & & 1.000 \\
\hline Non-user & $11(68.8)$ & $6(75.0)$ & $5(62.5)$ & \\
\hline User & $5(31.2)$ & $2(25.0)$ & $3(37.5)$ & \\
\hline \multicolumn{5}{|l|}{ Bone turnover marker } \\
\hline Bone-specific alkaline phos-phatase, $\mathrm{U} / \mathrm{l}$ & $25.4 \pm 7.8$ & $27.4 \pm 8.4$ & $23.5 \pm 7.1$ & 0.338 \\
\hline Collagen type I cross-linked & $14.0 \pm 6.0$ & $12.4 \pm 1.9$ & $15.6 \pm 8.3$ & 0.302 \\
\hline \multicolumn{5}{|l|}{$\mathrm{N}$ telopeptide, nnmol BCE/1 } \\
\hline \multicolumn{5}{|l|}{$\begin{array}{l}\text { Lumber dual-energy X-ray } \\
\text { absorptiometry }\end{array}$} \\
\hline Bone mineral density, $\mathrm{g} / \mathrm{cm}^{2}$ & $0.66 \pm 0.12$ & $0.62 \pm 0.14$ & $0.70 \pm 0.10$ & 0.182 \\
\hline \multicolumn{5}{|l|}{ Upper gastrointestinal find-ings } \\
\hline Reflux esophagitis, n (\%) & & & & 1.000 \\
\hline No & $16(100.0)$ & $8(100.0)$ & $8(100.0)$ & \\
\hline Yes & $0(0.0)$ & $0(0.0)$ & $0(0.0)$ & \\
\hline Hiatal hernia, n (\%) & & & & 0.608 \\
\hline No & $10(62.3)$ & $4(50.0)$ & $6(75.0)$ & \\
\hline Yes & $6(37.6)$ & $4(50.0)$ & $2(25.0)$ & \\
\hline Peptic ulcer disease, n (\%) & & & & 0.569 \\
\hline No & $12(75.0)$ & $5(62.5)$ & $7(87.5)$ & \\
\hline Yes & $4(25.0)$ & $3(37.5)$ & $1(12.5)$ & \\
\hline
\end{tabular}


Table I. Continued.

\begin{tabular}{lccc}
\hline Patient profile & Total $(\mathrm{n}=16)$ & Alfacalcidol $(\mathrm{n}=8)$ & Alendronate $(\mathrm{n}=8)$ \\
\hline $\begin{array}{l}\text { Questionnaire } \\
\begin{array}{l}\text { Frequency scale for the symptoms } \\
\text { of gastroesopha-geal reflux disease score }\end{array}\end{array}$ & $6.5 \pm 6.1$ & $3.6 \pm 3.0$ & $9.4 \pm 7.2$ \\
\hline
\end{tabular}

Values are presented as means \pm standard deviation.

and $0.75 \pm 010 \mathrm{~g} / \mathrm{cm}^{2}$ for the AD group. The percentage changes in lumbar BMD from baseline to the end of one year of therapy were $-0.4 \pm 4.0 \%$ for the AC group and $6.8 \pm 6.3 \%$ for the AD group, with significantly effective lumbar BMD findings identified in the AD group ( $\mathrm{P}=0.015$; Fig. 1).

Bone turnover markers. The baseline values of bone turnover markers in the $\mathrm{AC}$ and $\mathrm{AD}$ groups, respectively were as follows: BAP (U/1), 27.4 \pm 8.4 vs. $23.5 \pm 7.1 \quad(\mathrm{P}=0.338)$; NTX (nmol BCE/l), $12.4 \pm 1.9$ vs. $15.6 \pm 8.3(\mathrm{P}=0.302)$. After one year of treatment, the values of bone turnover markers in the $\mathrm{AC}$ and AD groups, respectively were as follows: BAP (U/1), 23.6 \pm 7.3 vs. $15.1 \pm 4.1$; NTX (nmol BCE/1), 12.8 \pm 4.5 vs. 12.6 \pm 8.7 . When comparing the percentage change between baseline and the end of one year of treatment, the AC group demonstrated less of a change over time in BAP $(-12.1 \pm 25.5 \%)$ compared with the AD group $(-32.7 \pm 21.7 \%)(\mathrm{P}=0.103)$, and less of a change over time in NTX $(+2.4 \pm 25.7 \%)$ compared with the AD group $(-15.9 \pm 21.3 \%)(\mathrm{P}=0.143)$; although the difference was not statistically significant (Figs. 2 and 3).

Upper GI findings. Baseline findings of the upper GI endoscopy (Table I) indicated no RE in either treatment group, $\mathrm{HH}$ in $50.0 \%$ of the AC group vs. $25.0 \%$ of the AD group ( $\mathrm{P}=0.608)$, PUD in $37.5 \%$ of the $\mathrm{AC}$ group vs. $12.5 \%$ of the $\mathrm{AD}$ group $(\mathrm{P}=0.569)$. No novel findings of RE or PUD were observed from baseline to the end of one year of treatment in either group.

FSSG score. The mean baseline values for FSSG were 3.6 \pm 3.0 for the $\mathrm{AC}$ group vs. $9.4 \pm 7.2$ for the $\mathrm{AD}$ group $(\mathrm{P}=0.056)$. After one year of treatment, the mean FSSG values were $4.5 \pm 2.8$ for the AC group and 8.3 \pm 5.1 for the AD group. The change from baseline FSSG scores to the end of one year of treatment was not significantly different in either group ( $\mathrm{AC}$ group, $\mathrm{P}=0.556$; AD group, $\mathrm{P}=0.723$ ), respectively (Fig. 4).

Safety analysis. Of the 22 patients that participated in this study, six patients were excluded as mentioned above. In each group, the side effect was mild nausea and the frequency of side effects was the same between the two study groups (one case in each group). New bone fractures were not observed from baseline to the end of one year of treatment in either group.

\section{Discussion}

To the best of our knowledge, this is the first prospective, randomized, open-label study to investigate the therapeutic efficacy of $\mathrm{AC}$ and $\mathrm{AD}$, as estimated by lumbar BMD changes

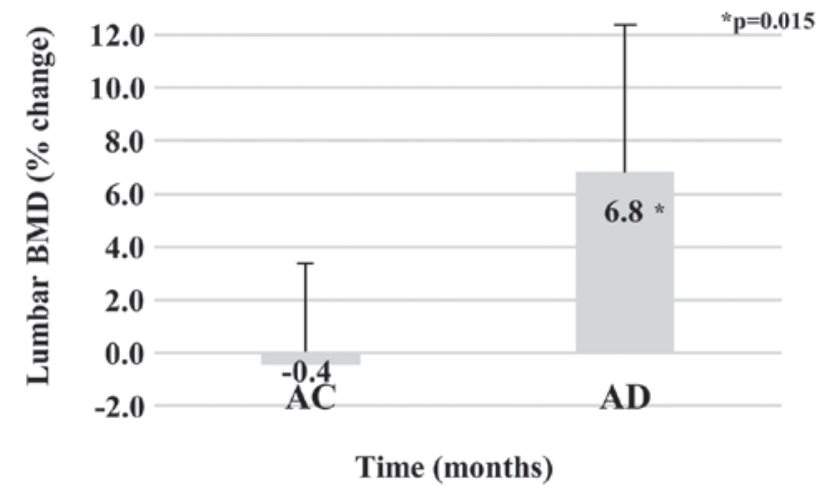

Figure 1. Percentage change of lumbar BMD from baseline to one year after treatment in the AC and AD groups. The percentage change in lumbar BMD from baseline to the end of one year of therapy was $-0.4 \pm 4.0 \%$ for the AC group and $6.8 \pm 6.3 \%$ for the $\mathrm{AD}$ group $(\mathrm{P}=0.015)$. Thus, there was a greater increase in lumbar BMD after one year of treatment with AD compared with AC. BMD, bone mineral density; AC, alfacalcidol; AD, alendronate.

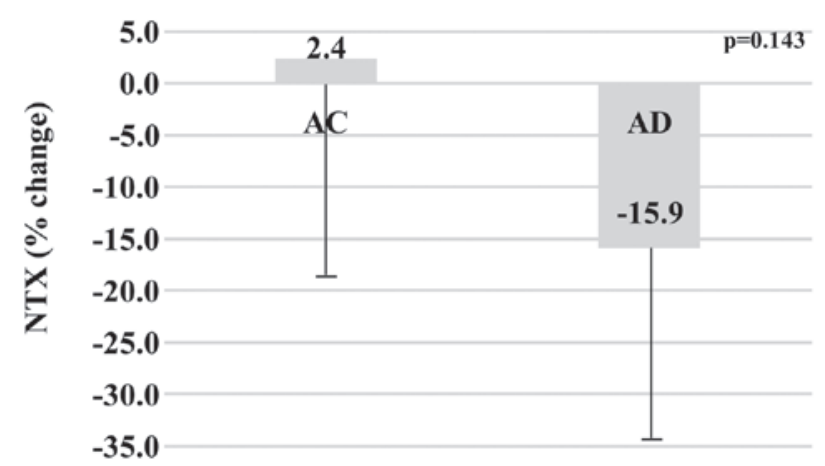

Figure 2. Percentage change of NTX from baseline to one year after treatment in the $\mathrm{AC}$ and $\mathrm{AD}$ groups. In the $\mathrm{AC}$ and $\mathrm{AD}$ groups, the percentage change of NTX was $2.4 \pm 25.7 \%$ vs. $-15.9 \pm 21.3 \%$ ( $P=0.143$, with no significant difference in percentage change of NTX between the two groups. NTX, collagen type-I cross-linked N-telopeptide; AC, alfacalcidol; AD, alendronate.

in osteoporotic patients using concomitant PPIs. Although a recent prospective study comparing $\mathrm{AD}$ and $\mathrm{AC}$ indicated that $\mathrm{AD}$ was more efficacious than $\mathrm{AC}$ in increasing lumber BMD (14), the current study of osteoporotic patients using PPIs demonstrated that lumbar BMD change following a one-year treatment with AD was greater than that observed with AC treatment. Furthermore, a previous report indicated that PPI use was associated with a dose-dependent loss of AD anti-fracture efficacy (10). According to certain Japanese prospective studies, the lumbar BMD increase at one year after AD treatment was $\sim 6 \%(14,15)$ and in the current study, 


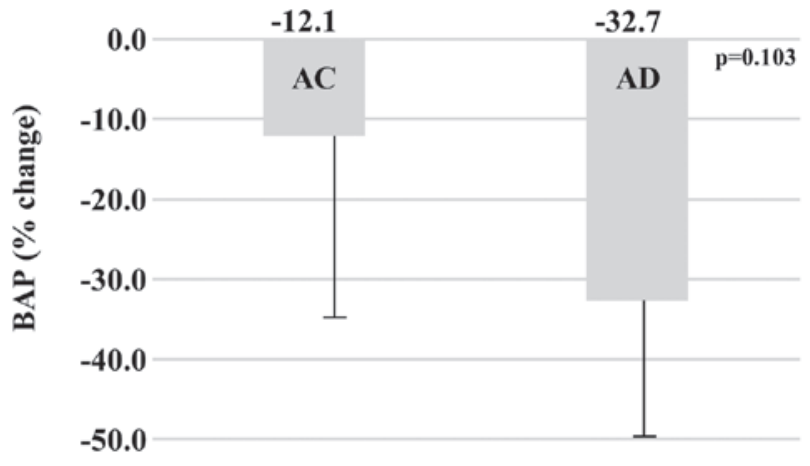

Figure 3. Percentage change of BAP from baseline to one year after treatment in the $\mathrm{AC}$ and $\mathrm{AD}$ groups. In the $\mathrm{AC}$ and $\mathrm{AD}$ groups, the percentage change of $\mathrm{BAP}$ was $-12.1 \pm 25.5 \%$ vs. $-32.7 \pm 21.7 \%$ ( $\mathrm{P}=0.103$ ), with no significant difference in percentage change of BAP between the two groups. BAP, bone-specific alkaline-phosphatase; $\mathrm{AC}$, alfacalcidol; $\mathrm{AD}$, alendronate.
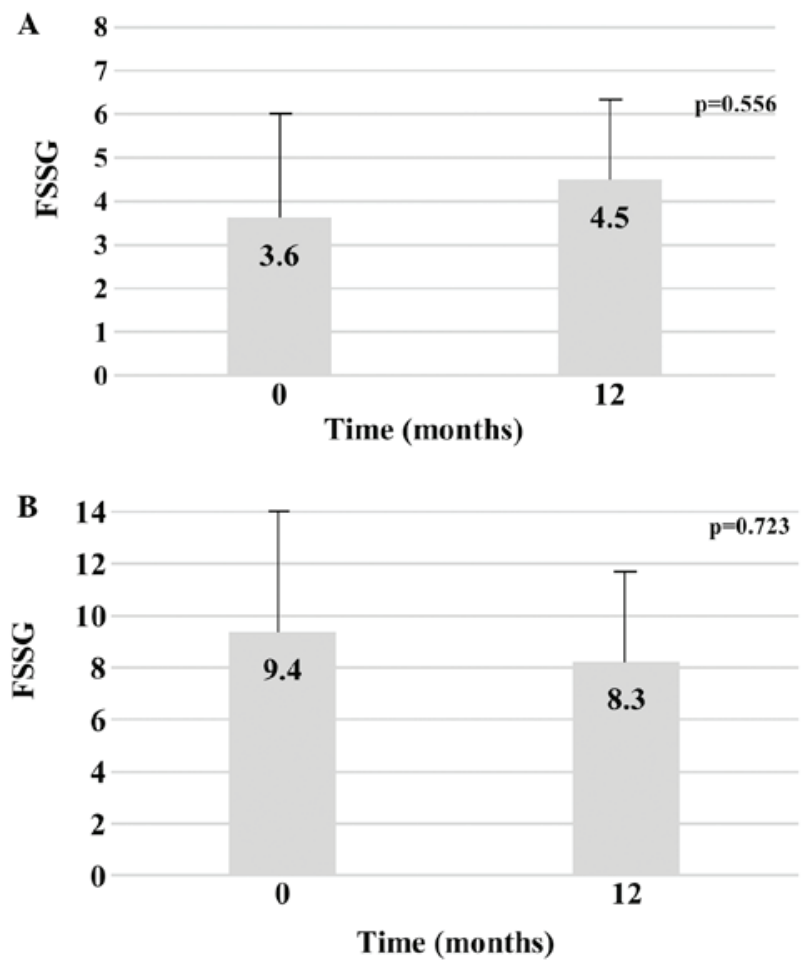

Figure 4. Change of FSSG from baseline to one year after treatment in the $\mathrm{AC}$ and $\mathrm{AD}$ groups. (A) The mean baseline value for FSSG was 3.6 \pm 3.0 , and the mean value after one year of treatment was $4.5 \pm 2.8$ in the AC group. The change from baseline FSSG scores to the end of one year of treatment was not significantly different in the AC group $(\mathrm{P}=0.556)$. (B) The mean baseline value for FSSG was $9.4 \pm 7.2$, and the mean value after one year of treatment was $8.3 \pm 5.1$ in the AD group. The change from baseline FSSG scores to the end of one year of treatment was not significantly different in the AD group $(\mathrm{P}=0.723)$. FSSG, frequency scale for the symptoms of gastroesophageal reflux disease score; $\mathrm{AC}$, alfacalcidol; $\mathrm{AD}$, alendronate.

the lumbar BMD increase after one year of AD treatment in osteoporotic patients using PPIs (6.8\%) was similar to a previous study. However, a limitation of the present study was that the number of study subjects was small; thus, further large prospective studies are required to determine the effect of $\mathrm{AD}$ in osteoporotic patients using concomitant PPIs.

It is hypothesized that PPIs attenuate the therapeutic effect of bisphosphonate as follows: PPIs may decrease the absorption of calcium; the dissolution of calcium carbonate is a $\mathrm{pH}$-dependent process and gastric $\mathrm{pH}$ is particularly important for calcium absorption (16). As PPIs strongly suppress gastric acid secretion, the dissolution of calcium carbonate is inhibited by gastric juice with a high $\mathrm{pH}$ and, as a result, calcium absorption may decrease. Similarly, an association between PPI use and bone fracture is suggested in western countries (17); however, certain studies did not report any association between PPI use and bone fracture (18) and there are few prospective studies regarding the association between PPI use and bone fracture.

It was reported that the occurrence of GI adverse events was an independent determinant of persistence with bisphosphonate therapy (19) and adherence to bisphosphonate treatment may decrease due to GI adverse events. However adherence to the bisphosphonate treatment schedule was good in the present study (data not shown).

It was reported that PPIs suppress bone resorption adversely by inhibiting the vacuolar proton pump of the osteoclast (20). However, it was reported that the concentrations of PPIs required for the inhibition of the osteoclast proton pump are markedly higher than the tolerable physiological concentrations (21). Gertz et al (22) reported that increasing gastric $\mathrm{pH}$ by infusion of ranitidine was associated with a doubling of $\mathrm{AD}$ bioavailability. Recently, Itoh et al (23) reported that risedronate administration in combination with a PPI may be more effective for treating osteoporosis and for improving physical fitness than treatment with risedronate alone, although they evaluated the BMD of the trabecular bone using quantitative computer tomography (23).

According to previous reports, the lumbar BMD increase following one year of AC treatment was $\sim 1 \%(24,25)$, while the current study indicated a lumbar BMD change of $-0.4 \%$ after one year of $\mathrm{AC}$ treatment. It was previously reported that bisphosphonates reduce $\sim 50 \%$ of bone turnover markers (15); however, no significant difference in bone turnover markers was identified in the present study. A limitation of the current investigation was that the number of study subjects was small; therefore, the effect of $\mathrm{AD}$ on bone turnover markers may not have been apparent.

It was suggested that osteoporotic patients exhibiting lumbar pressure fractures or kyphosis are at risk of $\operatorname{GERD}(26,27)$. Miyakoshi et al (28) also reported that increases in the angle of lumbar kyphosis and the number of lumbar vertebral fractures may represent very important risk factors for GERD in osteoporotic patients. However, there are few reports about the association between GERD symptoms using FSSG and bisphosphonates. In the current study, the FSSG score did not change after the one-year treatment with AD; therefore, the increase in GERD symptoms triggered by long-term use was not observed.

Since there were no significant changes in frequency or severity of side effects in the two treatment groups in this study, concomitant PPI use with AD may present as a safe therapeutic strategy. Furthermore, no increased findings of RE or PUD were observed over the one year of treatment with either AD or AC. As the residence time in the esophagus of the medication was considered a mechanism of the risk for esophagitis (4), the patients in the current study were instructed comprehensively about the appropriate dosing regimen (taking 
a tablet with enough water and remaining upright for $\geq 30 \mathrm{~min}$ before the first food of the day).

There were certain limitations of the current study. The study was not a double-blind trial, but an open-labeled study. The number of study subjects was particularly small; therefore, a large prospective multicenter trial is required. Furthermore, patients used different PPIs, which may have influenced certain results, such as lumbar BMD and the FSSG score. Family histories of osteoporosis or certain other important risk factors, such as exercise, sunlight exposure, dietary calcium intake, or the use of over-the-counter medication and other nutrients were not investigated.

In conclusion, the present study demonstrated via lumbar BMD change that a one-year treatment with AD was more efficacious than with $\mathrm{AC}$ in osteoporotic patients using PPIs. Furthermore, as with previous reports, the percentage change in lumbar BMD following one year of AD treatment was similar $(6.8 \%)$ in osteoporotic patients using PPIs. However, additional, large prospective multicenter trials are required to further clarify the efficacy of bisphosphonate administration with PPIs in osteoporosis treatment.

\section{References}

1. Iki M: Epidemiology of osteoporosis in Japan. Clin Calcium 22: 797-803, 2012 (In Japanese).

2. Liberman UA, Weiss SR, Bröll J, Minne HW, Quan H, Bell NH, Rodriguez-Portales J, Downs RW Jr, Dequeker J, Favus M, et al; The Alendronate Phase III Osteoporosis Treatment Study Group: Effect of oral alendronate on bone mineral density and the incidence of fractures in postmenopausal osteoporosis. N Engl J Med 333: 1437-1443, 1995.

3. de Groen PC, Lubbe DF, Hirsch LJ, Daifotis A, Stephenson W, Freedholm D, Pryor-Tillotson S, Seleznick MJ, Pinkas H and Wang KK: Esophagitis associated with the use of alendronate. N Engl J Med 335: 1016-1021, 1996.

4. Graham DY, Malaty HM and Goodgame R: Primary amino-bisphosphonates: A new class of gastrotoxic drugs - comparison of alendronate and aspirin. Am J Gastroenterol 92: 1322-1325, 1997.

5. Yoshimura N, Muraki S, Oka H, Kawaguchi H, Nakamura K and Akune T: Cohort profile: Research on osteoarthritis/osteoporosis against disability study. Int J Epidemiol 39: 988-995, 2010.

6. Nagasue T, Nakamura S, Kochi S, Kurahara K, Yaita H, Kawasaki K and Fuchigami T: Time trends of the impact of Helicobacter pylori infection and nonsteroidal anti-inflammatory drugs on peptic ulcer bleeding in Japanese patients. Digestion 91 : 37-41, 2015.

7. Kinoshita Y, Kawanami C, Kishi K, Nakata H, Seino Y and Chiba T: Helicobacter pylori independent chronological change in gastric acid secretion in the Japanese. Gut 41: 452-458, 1997.

8. Fujiwara Y and Arakawa T: Epidemiology and clinical characteristics of GERD in the Japanese population. J Gastroenterol 44: 518-534, 2009.

9. Malfertheiner P, Fass R, Quigley EM, Modlin IM, Malagelada JR, Moss SF, Holtmann G, Goh KL, Katelaris P, Stanghellini V, et al: Review article: From gastrin to gastro-oesophageal reflux disease - a century of acid suppression. Aliment Pharmacol Ther 23: 683-690, 2006.

10. Abrahamsen B, Eiken P and Eastell R: Proton pump inhibitor use and the antifracture efficacy of alendronate. Arch Intern Med 171: 998-1004, 2011.

11. Orimo H, Hayashi Y, Fukunaga M, Sone T, Fujiwara S, Shiraki M, Kushida K, Miyamoto S, Soen S, Nishimura J, et al; Osteoporosis Diagnostic Criteria Review Committee: Japanese Society for Bone and Mineral Research: Diagnostic criteria for primary osteoporosis: Year 2000 revision. J Bone Miner Metab 19: 331-337, 2001.
12. Lundell LR, Dent J, Bennett JR, Blum AL, Armstrong D, Galmiche JP, Johnson F, Hongo M, Richter JE, Spechler SJ, et al: Endoscopic assessment of oesophagitis: Clinical and functional correlates and further validation of the Los Angeles classification. Gut 45: 172-180, 1999.

13. Kusano M, Shimoyama Y, Sugimoto S, Kawamura O, Maeda M, Minashi K, Kuribayashi S, Higuchi T, Zai H, Ino K, et al: Development and evaluation of FSSG: Frequency scale for the symptoms of GERD. J Gastroenterol 39: 888-891, 2004

14. Shiraki M, Kushida K, Fukunaga M, Kishimoto H, Taga M, Nakamura T, Kaneda K, Minaguchi H, Inoue T, Morii H, et al; The Alendronate Phase III Osteoporosis Treatment Research Group: A double-masked multicenter comparative study between alendronate and alfacalcidol in Japanese patients with osteoporosis. Osteoporos Int 10: 183-192, 1999.

15. Uchida S, Taniguchi T, Shimizu T, Kakikawa T, Okuyama K, Okaniwa M, Arizono H, Nagata K, Santora AC, Shiraki M, et al: Therapeutic effects of alendronate $35 \mathrm{mg}$ once weekly and $5 \mathrm{mg}$ once daily in Japanese patients with osteoporosis: A double-blind, randomized study. J Bone Miner Metab 23: 382-388, 2005.

16. Sipponen P and Härkönen M: Hypochlorhydric stomach: A risk condition for calcium malabsorption and osteoporosis? Scand J Gastroenterol 45: 133-138, 2010.

17. Yang YX, Lewis JD, Epstein S and Metz DC: Long-term proton pump inhibitor therapy and risk of hip fracture. JAMA 296: 2947-2953, 2006.

18. Kaye JA and Jick H: Proton pump inhibitor use and risk of hip fractures in patients without major risk factors. Pharmacotherapy 28: 951-959, 2008.

19. Penning-van Beest FJ, Goettsch WG, Erkens JA and Herings RM: Determinants of persistence with bisphosphonates: A study in women with postmenopausal osteoporosis. Clin Ther 28: 236-242, 2006.

20. Tuukkanen J and Väänänen HK: Omeprazole, a specific inhibitor of $\mathrm{H}+-\mathrm{K}+-\mathrm{ATPase}$, inhibits bone resorption in vitro. Calcif Tissue Int 38: 123-125, 1986.

21. Mattsson JP, Väänänen $K$, Wallmark B and Lorentzon P: Omeprazole and bafilomycin, two proton pump inhibitors: Differentiation of their effects on gastric, kidney and bone $\mathrm{H}(+)$-translocating ATPases. Biochim Biophys Acta 1065: 261-268, 1991.

22. Gertz BJ, Holland SD, Kline WF, Matuszewski BK, Freeman A, Quan H, Lasseter KC, Mucklow JC and Porras AG: Studies of the oral bioavailability of alendronate. Clin Pharmacol Ther 58: 288-298, 1995.

23. Itoh S, Sekino Y, Shinomiya K and Takeda S: The effects of risedronate administered in combination with a proton pump inhibitor for the treatment of osteoporosis. J Bone Miner Metab 31: 206-211, 2013.

24. Orimo H, Shiraki M, Hayashi Y, Hoshino T, Onaya T, Miyazaki S, Kurosawa H, Nakamura T and Ogawa N: Effects of 1 alpha-hydroxyvitamin D3 on lumbar bone mineral density and vertebral fractures in patients with postmenopausal osteoporosis. Calcif Tissue Int 54: 370-376, 1994.

25. Shikari M, Kushida K, Yamazaki K, Nagai T, Inoue T and Orimo H: Effects of 2 years' treatment of osteoporosis with 1 alpha-hydroxy vitamin D3 on bone mineral density and incidence of fracture: A placebo-controlled, double-blind prospective study. Endocr J 43: 211-220, 1996.

26. Yoshimura M, Nagahara A, Ohtaka K, Shimada Y, Asaoka D, Kurosawa A, Osada T, Kawabe M, Hojo M, Yoshizawa T, et al: Presence of vertebral fractures is highly associated with hiatal hernia and reflux esophagitis in Japanese elderly people. Intern Med 47: 1451-1455, 2008.

27. Yamaguchi T, Sugimoto T, Yamada H, Kanzawa M, Yano S, Yamauchi $\mathrm{M}$ and Chihara $\mathrm{K}$ : The presence and severity of vertebral fractures is associated with the presence of esophageal hiatal hernia in postmenopausal women. Osteoporos Int 13: 331-336, 2002.

28. Miyakoshi N, Kasukawa Y, Sasaki H, Kamo K and Shimada Y: Impact of spinal kyphosis on gastroesophageal reflux disease symptoms in patients with osteoporosis. Osteoporos Int 20: 1193-1198, 2009. 